\title{
Small Remnants of the Rice Lake Plains Prove Important ... How Many Do We Need?
}

\author{
Paul M. CATLing
}

Agriculture and AgriFood Canada, Environmental Health, Biodiversity, Saunders Building, Central Experimental Farm, Ottawa K1A 0C6 Canada; e-mail: catlingp@agr.gc.ca

Catling, Paul M. 2008. Small remnants of the Rice Lake Plains prove important ... how many do we need? Canadian FieldNaturalist 122(1): 93-94.

Protecting large areas has a lot of well-documented advantages over protecting small areas, but small areas, especially with regard to rare plants, can be very important. This has been known for some time (e.g., Conner and McCoy 1979). One of the best articles about the long term species retention in very small areas is that of Reznicek (1987). In some situations it is possible to analyze data to test this "small area value" hypothesis, and data on remnants of the Rice Lake Plains is available to do it. (see Catling 2008).

Remnants of the plains with regionally rare and very restricted flora are known from the higher parts of the Oak Ridges moraine to the west, south and east of Rice Lake (Catling et al. 1992; Catling 2008). At least 42 relatively well-preserved and isolated remnants are known, and data on the total number of native species and number of regionally rare native species are available for 24 . These remnants vary in size from 0.1 to 16.7 ha and collectively contain 257 native species of which 111 are regionally rare.

A simple linear regression plot of species number and area for the 24 sites provides a trend line with significance values. (Figure 1). The line suggests that as size increases the number of species tends to increase. However, the model is not significant in either case (at $P=0.05$ level) and in fact is not even close to being significant $(P>0.16)$. In these data, speciesarea relationship is not important. It is clear that some smaller sites such as 29 (a 1.64 ha remnant in and near Goodrich-Loomis Conservation Area) contain almost as much biodiversity as much larger sites such as 12 (8.82 ha of prairies and savanna at Alderville First Nation), and a number of small sites are positioned quite high above the line. The regionally rare species have presumably been present at these small sites for more than a hundred years, since the plains were largely
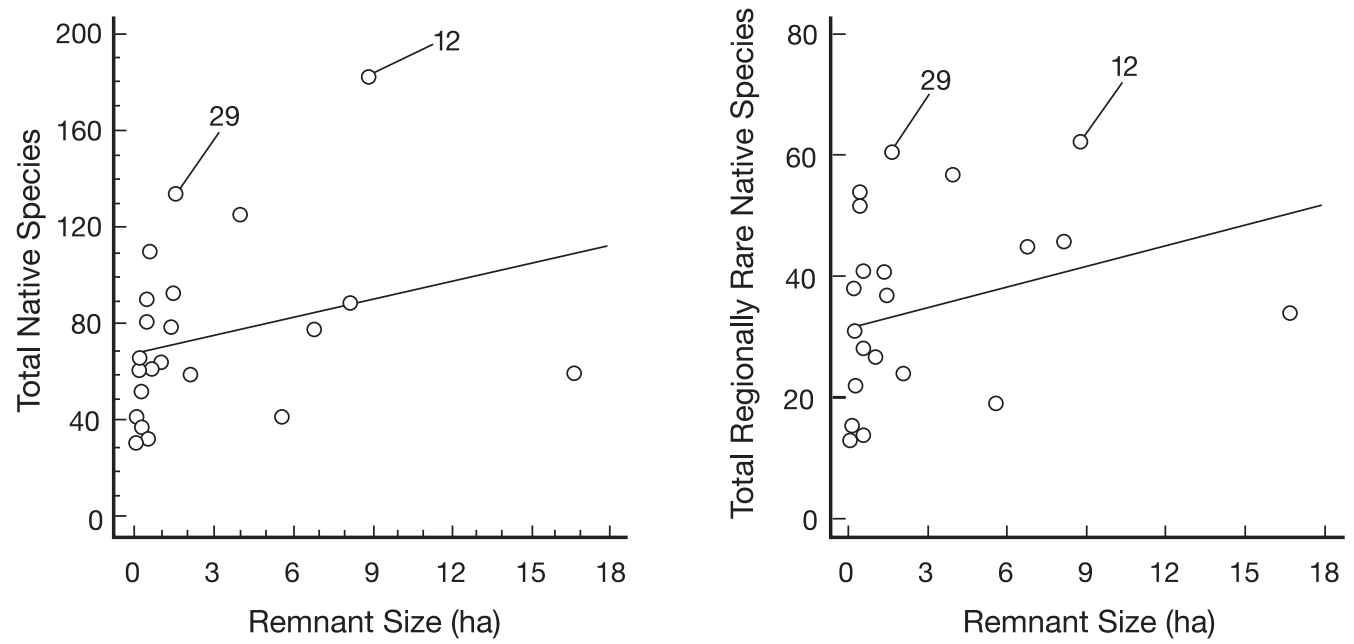

FIGURE 1. Trend lines based on simple linear regression for native species (left) and regionally rare native species (right). Although larger sites have more species, the relationship is not significant in this analysis (the $F$ ratios are 0.20 for the left and 0.17 for the right), and less than $9 \%\left(R^{2}=7.3\right.$ left and 8.5 right $)$ of the variation in number of species is explained by remnant size. 
reduced to remnants by 1885 . Although there may be increases in abundance of native species within a site and in abandoned farmland adjacent to a relict site (Catling and King 2008), there is little evidence that rare native species have spread to any of these sites since they became isolated in a landscape dominated by aggressive aliens such as Smooth Brome Grass. Thus some of the smaller remnants of the Rice Lake Plains are rich and persistent. Despite their persistence, they are in many cases now being overwhelmed by increasingly problematic invasive species and management is necessary if the rare native species are to survive and/or increase in abundance (Catling and King 2008). Of course the threat of invasives is the same for big or small areas.

Some may say that we are still better off with the larger area for a variety of reasons - and that may be true; but actually to maximally protect plant biodiversity, we may get more with a number of smaller areas (for the same price). The more important question though is: how many sites do we need to protect? This of course depends on the objective. In the present case, if we make the objective the maximum protection of plant biodiversity, then it is not too difficult to get an answer. The richest site (12) includes only 62 of 111 regionally rare plant species - a little over half. This lead site is lacking many distinctive prairie species such as Prairie Smoke (Geum triflorum) and Early Buttercup (Ranunculus fascicularis) which are present in the much smaller site 29 , which with 60 regionally rare species, has almost the same number. Protecting these two sites we still have only $77 \%$ of the regionally rare plants. Consecutively protecting sites with maximum biodiversity, we need 8 sites to get $90 \%$. We might get $95 \%$ with 8 sites using an optimization procedure or $100 \%$ with 10 sites.

It should be no surprise that remnants vary. The original ecosystem probably varied in composition spatially due to variation in soil content, moisture, slope, exposure and random events such as fire. Remnants are different from each other, although they have a lot in common, like the parts of a jigsaw puzzle.

It may be said that we could introduce species to augment numbers at a site, but this does not always work because sites vary in environmental conditions. We know that conditions are suitable where the plant is growing, but at another site they may not be, so transplanting to augment biodiversity does not always work if the objective is a functioning ecosystem rather than a garden. For more on transplanting see Fahselt (1988), Allen (1994), Schemske et al. (1994), Sperry (1994), Pavlick (1996), and Hubbard et al. (2001).

So we need about 10 well-chosen remnants to protect the regionally rare flora (and more would be better since we have not taken abundance of species into account), but plants are not the only thing. Consider, for example, rare insects with a physical requirement for open sand, or the need for temporary pools to support toads (Anaxyrus [Buto])which in turn support Hognose Snakes (Heterodon). Soon the number of isolated remnants required to adequately protect the vestiges of the biodiversity of the Rice Lake Plains is dozens, and this is true for many other landscapes as well.

The data on Rice Lake Plains remnants suggest that small sites are worth considering for protection and that many sites may be required to protect the remaining biodiversity. Large areas are desirable but conservation actions should be clever and opportunistic as well as idealistic. These ideas may be news to many people who think that one big example is enough, but fortunately this is not news to the Nature Conservancy of Canada. Over the last decade NCC has played a major role in protecting what is left of the Rice Lake Plains.

\section{Literature Cited}

Allen, W. H. 1994. Re-introduction of endangered plants. Bioscience 44: 65-69.

Catling, P. M. 2008. The extent and floristic composition of the Rice Lake Plains based on remnants. Canadian FieldNaturalist 122: 1-20.

Catling, P. M., V. R. Catling, and S. M. McKay-Kuja. 1992. The extent and floristic composition of the Rice Lake Plains based on historical records. Canadian FieldNaturalist 106: 73-86.

Catling. P. M., and B. King. 2008. Natural recolonization of cultivated land by prairie plants and its enhancement by removal of Scots Pine, Pinus sylvestris. Canadian FieldNaturalist 121: 201-205.

Conner, E. F., and E. D. McCoy. 1979. The statistics and biology of the species-area relationship. American Naturalist 113: 791-833.

Fahselt, D. 1988. The dangers of transplantation as a conservation technique. Natural Areas Journal 8: 238- 244.

Hubbard, L., B. Ertter, A. Dennis, and C. Baskin. 2001. Statement opposing transplantation as mitigation for impacts to rare plants. Fremontia 29: 66-67.

Pavlik, B. M. 1996. Defining and measuring success. Pages 127-155 in Restoring Diversity. Strategies for Reintroduction of Endangered Plants. Edited by D. A. Falk, C. I. Millar and M. Oldwell. Island Press, Washington, D.C.

Reznicek, A. A. 1987. Are small preserves worthwhile for plants? Endangered Species Update 5(2): 1-3.

Schemske, D. W., B. C. Husband, M. H. Ruckelshaus, C. Goodwillie, I. M. Parker, and J. G. Bishop. 1994. Evaluating approaches to the conservation of rare and endangered plants. Ecology 75: 584-606.

Sperry, T. M. 1994. The Curtis Prairie restoration, using the single-species planting method. Natural Areas Journal 14: 124-127.

Received 7 November 2008

Accepted 13 November 2008 